\title{
Iniciação às Práticas de Saúde: Bricolagem na Seleção de Conteúdos
}

\author{
Initiation in Health Practices: Bricolage in \\ Content Selection
}

José Ivo Pedrosa

\section{PALAVRAS-CHAVE: \\ - Prática Médica; \\ - Ensino na Saúde; \\ - Metodologia.}

Recebido em: 03/10/2012

Reencaminhado em: 24/02/2013

Aprovado em: 20/05/2013

REVISTA BRASILEIRA DE EDUCAÇÃO MÉDICA

\section{RESUMO}

O tema Práticas de Saúde apresenta-se como polissêmico, possibilitando múltiplas abordagens teóricas e metodológicas. Para definir o conteúdo da disciplina Iniciação às Práticas de Saúde do curso médico da Universidade Federal do Piauí, operou-se a bricolagem entre inúmeros significados de práticas de saúde, ordenando e conectando dimensões da prática médica aos princípios do SUS e ao sentido de emancipação e autonomia da prática pedagógica, apontando que temas dessa natureza podem ser contextualizados e organizados sob a forma de disciplina utilizando-se a bricolagem para articular aspectos aparentemente isolados e invisíveis, cujo sentido é atribuído intencionalmente pelo professor.

The polysemic nature of health care practices allow multiple theoretical and methodological approaches to the topic. To define the content of the subject Initiation in Health Practices in the Medicine Course at the Federal University of Piaui entailed a bricolage of several different meanings of health practices, arranging and connecting aspects of medical practice to the principles of the SUS and to the sense of empowerment and autonomy of pedagogical practice, pointing out that such topics can be contextualized and organized in the form of a discipline by making using of bricolage to relate seemingly isolated and invisible aspects, the meaning of which is intentionally given by the teacher. 


\section{INTRODUÇÃO}

A articulação do processo de formação de médicos com os serviços de saúde, organizados em sistemas de saúde regulados pelos estados nacionais e, na maioria das vezes, sob a égide dos direitos sociais, tem demandado contínuos esforços em sua concretização, considerando que este processo necessita de estruturas, ambientes de formação de pessoas, tecnologias e informações científicas nem sempre coerentes com as demandas da população ou expressas nas intenções das políticas.

Tais esforços se justificam diante da exigência de profissionais para responder às necessidades contemporâneas da sociedade, cujo processo de formação deve resultar da conexão com o sistema de atenção e organização dos serviços, considerando a população como coprodutora e direcionadora das necessidades e demandas de ambos os sistemas ${ }^{1}$.

Desde o final do século passado, movimentos de reformas nos sistemas de saúde passaram a induzir modificações nos cursos médicos - como Medicina Integral, Medicina Preventiva, Medicina de Comunidade, Atenção Primária em Saúde e Saúde da Família - , introduzindo disciplinas de outros campos do conhecimento, principalmente da área de humanidades, tais como sociologia e antropologia da saúde, integração ensino e serviço, e metodologias problematizadoras².

Atualmente, a articulação entre ensino e serviço tem sido implementada por meio de ações integrantes de políticas públicas voltadas à aproximação da formação com os serviços públicos, como o Programa de Educação pelo Trabalho em Saúde (PET-Saúde),

utilizando estratégias complementares, focadas no eixo dos cenários de prática e no processo ensino-aprendizagem que se dá na rede de serviços, em uma relação que envolve o docente, o estudante, a equipe de saúde dos serviços e os usuários do SUS (p. 4$)^{3}$.

No Brasil, com a implantação do SUS, têm sido introduzidas nos cursos médicos disciplinas que tomam como objeto de ensino o sistema de saúde brasileiro em termos de seus princípios éticos e políticos e diretrizes organizacionais, diferenciando-se de disciplinas do campo da saúde pública que foram incorporadas aos currículos, como administração de serviços, medidas de profilaxia, educação em saúde e outras.

Em 2000, foi criada a disciplina Introdução às Práticas de Saúde (IPS) no curso médico da Universidade Federal do Piauí (UFPI), ofertada no primeiro ano, obrigatória, cujo objetivo geral era apresentar aos alunos de Medicina os serviços públicos de saúde nos municípios.

Este artigo reflete a organização do conteúdo da disciplina no contexto atual, considerando que as práticas de saúde cons- tituem processos relacionais em que as "culturas" (do serviço, dos médicos, das enfermeiras, dos agentes, da população) conformam mosaicos de tecnologias leves montados em ato, no processo de trabalho em saúde ${ }^{4}$. Aspectos dessas práticas de saúde encontram-se integrados ao cotidiano de diferentes setores da população, conformando-lhes determinado modo de $v$ vida $^{5}$, e expressam, além da dimensão tecnológica, interações subjetivas entre população, profissionais e gestores que acontecem nos espaços coletivos e os modos singulares como cada indivíduo vive, interpreta e expressa suas exigências ${ }^{6}$.

A Política Nacional de Humanização no SUS, por exemplo, expõe dimensões das práticas de saúde que deixam à mostra seu caráter subjetivo ${ }^{7}$. Apesar destas constatações, o processo de formação permanece reduzindo a prática em saúde à sua dimensão técnica e profissional ${ }^{8}$.

Para Ayres', a racionalidade prática das ações de saúde pode ser dimensionada a partir da sensibilidade de capacidade de respostas dos profissionais, serviços, programas e políticas em relação ao êxito de suas ações, entendendo-se como tal o melhor uso dos conhecimentos técnicos possibilitados pela tecnociência da saúde diante dos projetos de felicidade de seus destinatários.

Definir o conteúdo da disciplina IPS requer o questionamento de quais aspectos das práticas de saúde devem ser sistematizados, organizados e apresentados aos estudantes iniciantes do curso médico em um contexto globalizado no qual convivem iniquidades em saúde, emergência de novas infecções, novos riscos ambientais e comportamentais, rápida transição demográfica e epidemiológica, e intenso desenvolvimento científico e tecnológico.

Que dimensões intrínsecas à prática médica poderiam ser apresentadas aos estudantes além de suas características de campo de conhecimento privilegiado que incorpora crescentes inovações tecnológicas, que gera oportunidades de mercado de trabalho, salários, poder técnico e político?

Como desconstruir a representação simbólica do "mundo médico" para os discentes iniciantes, ancorada em estereótipos construídos pela sociedade ${ }^{9}$ que dificultam a perspectiva de que a formação e a profissão de médico, respectivamente processo e intervenção, no século XXI, devem primar pela qualidade em suas ações, ser desenvolvidas em equipe, ter por base serviços organizados sob princípios éticos e centrados nos interesses de pacientes e da população ${ }^{10}$ ?

Tais questionamentos orientaram a seleção dos conteúdos da disciplina, cujo processo consistiu em identificar e coletar o material disponível sobre o tema Práticas de Saúde conceitos, relatos de experiências, opiniões, notícias, atas de reuniões, impressões, fragmentos, textos, etc. - , agrupando-o em três conjuntos: no primeiro, os elementos referentes à 
pluralidade na abordagem da temática Práticas de Saúde; no segundo, os conteúdos das ementas de disciplinas correlatas existentes em alguns cursos médicos das Instituições Federais de Ensino Superior (Ifes) do Brasil; no terceiro, elementos provenientes das condições estruturais da disciplina, como carga horária, cronograma e normas.

A partir daí, procedeu-se à identificação das conexões entre estes elementos e a seu reagrupamento em três eixos: as dimensões da prática médica, os princípios do Sistema Único de Saúde (SUS) e a contribuição da disciplina para a compreensão das práticas de saúde (e médicas em particular) como práticas emancipatórias e promotoras de autonomia para os envolvidos (profissionais e usuários do sistema de saúde).

Por meio de sucessivas bricolagens entre as conexões possíveis no universo de possibilidades de compreensão do tema, foram construídas unidades temáticas que, ao serem analisadas no contexto atual das proposições sobre mudanças na formação na saúde, apontaram os conteúdos da disciplina.

\section{CENÁRIO}

O curso de Medicina da Universidade Federal do Piauí tem origem na Faculdade de Medicina do Piauí (Famepi), criada em 1966 como estabelecimento isolado de ensino superior, sediada na cidade de Teresina e mantida pelo Estado do Piauí por meio da Fundação de Ensino Superior do Piauí (Fespi). Em 1972, foi criada a Fundação Universidade Federal do Piauí (Fufpi), que, tomando como modelo a Universidade de Brasília, estruturou as unidades de ensino em Centros - Centro de Ciências da Saúde (CCS), integrando a Faculdade de Odontologia (Fopi), cursos de Enfermagem e Educação Física, criados em 1974, Nutrição, em 1976, e Farmácia, em 1992.

O curso de Medicina tem 8.985 horas, sendo 1.875 horas para o ciclo básico, 2.250 no ciclo profissionalizante, 150 horas de Disciplinas Complementares Optativas e 4800 horas no internato. Nesta composição, as disciplinas de responsabilidade do Departamento de Medicina Comunitária - Iniciação às Práticas de Saúde, Bioestatística, Saúde Coletiva I, Saúde Coletiva II e Administração em Serviços de Saúde — são ofertadas no ciclo básico e ocupam $11,76 \%$ da carga horária total desse ciclo. No profissionalizante, não existem disciplinas do Departamento, também responsável pelo internato em Saúde Coletiva com 960 horas, 20\% do total correspondente a este período.

A disciplina Iniciação às Práticas em Saúde (IPS) foi introduzida na estrutura curricular juntamente com o internato em Saúde Coletiva no âmago do processo de discussão sobre as escolas médicas, motivado, no Brasil, pelos resultados da Comissão Nacional de Avaliação das Escolas Médicas (Cinaem) ${ }^{11}$, que demonstraram inadequação do formando em relação à re- alidade nacional, deficiência de estruturas e formação docente, uma das bases de formulação das Diretrizes Curriculares Nacionais para a Medicina.

A disciplina, com 45 horas-aula, ofertada no primeiro período, contempla em sua ementa: medicina social: aspectos teóricos e históricos; sujeitos e práticas de saúde; Programa Saúde da Família como prática de saúde numa comunidade; elementos de pesquisa em Atenção Básica; a relação médico-paciente: humanização do atendimento. Essa ementa foi definida em função da necessidade de aproximar a formação do médico do sistema de saúde, principalmente do então Programa de Saúde da Família, em rápida expansão na capital Teresina.

Em alguns casos, entretanto, a mudança nas escolas médicas brasileiras sugerida pela Cinaem significou tão somente o acréscimo de disciplinas de "conteúdo social", como Antropologia Social e Sociologia da Saúde, e adequações de carga horária. No caso do Piauí, a introdução da disciplina Iniciação às Práticas de Saúde e do internato em Saúde Coletiva não foi acompanhada de mudanças na estrutura, na cultura organizacional da escola médica e no projeto político pedagógico do curso.

Em 2010, emerge a necessidade de atualizar os conteúdos da disciplina IPS diante de um cenário em que conviviam: a frágil institucionalidade das atividades práticas, principalmente em unidades de saúde sob a responsabilidade do gestor municipal de saúde; o perfil esperado do médico formado pela instituição como o profissional com capacidade para lidar com a diversidade de comportamentos, crenças e ideias, reconhecendo os direitos dos pacientes ${ }^{12}$; e a articulação do Departamento com o Núcleo de Estudos em Saúde Pública (Nesp) da UFPI, espaço que abriga grupo de pesquisa com mestrandos e estudantes de graduação sobre ensino na saúde.

\section{PRÁTICAS DE SAÚDE E DIRECIONALIDADE DA MUDANÇA NA FORMAÇÃO MÉDICA}

Desde os anos 1980, inúmeras iniciativas vêm sendo realizadas no âmbito das escolas médicas, como modificações na estrutura curricular, introdução de novos cenários de aprendizagem e inovações metodológicas. No contexto do SUS, as Conferências Nacionais de Saúde e as Conferências Nacionais de Gestão do Trabalho e da Educação na Saúde ${ }^{13,14}$ têm evidenciado o distanciamento entre o produto das escolas médicas, sua distribuição geográfica e as necessidades do sistema, deliberando por políticas que articulem a formação, a demanda por serviços e as características epidemiológicas da população, configurando o ensino em saúde como objeto de programas e políticas governamentais interministeriais ${ }^{15,16}$.

A formação médica, comumente refratária a inovações, desde a publicação das Diretrizes Curriculares Nacionais 
(DCN) em $2001^{17}$, apresenta-se como um mosaico de diversas experiências que apresentam metodologias, cenários de prática e currículos inovadores. Este movimento reforça a ideia de que, para afirmar os princípios do SUS com base nos pressupostos da Reforma Sanitária, é necessário incluir, além dos gestores do sistema nos três níveis de governo e da sociedade civil, as instituições formadoras como determinantes que podem efetivamente alterar os cenários assistenciais e de formação historicamente consolidados ${ }^{18}$.

A Política Nacional de Educação Permanente para o SUS tem afirmado o papel do Sistema Único de Saúde como ordenador da formação e promovido o incentivo e apoio institucional às inovações articulando ensino e serviços ${ }^{3}$.

Dez anos após a publicação das Diretrizes Curriculares Nacionais, apesar da diversidade e multiplicidade de experiências inovadoras, persiste uma distância considerável entre a intenção e o gesto, ou seja, o produto das escolas médicas ainda se encontra distante do preconizado nos documentos oficiais ${ }^{19}$.

O processo de formação com base em competências implica algo mais que pressupostos e objetivos discursivos apresentados nas propostas de formação, pois abrange a definição da estrutura, conteúdos, formas de avaliação, monitoramento e processos pedagógicos envolvidos em cada competência ${ }^{20}$.

O conceito ampliado de saúde compreende a determinação social da saúde e da doença nos níveis distais, proximais e mediais, abrangendo as determinações da macroestrutura social, estilos e modos de vida em seus aspectos objetivos e subjetivos, práticas profissionais realizadas por atores institucionais e práticas populares legitimadas pela comunidade que valoriza e reconhece seus agentes, revelando uma complexidade que vai além da definição de competências profissionais explícitas nos documentos oficiais.

Esta reflexão integra o debate atual sobre a formação profissional e a efetividade da intervenção deste profissional para resolver problemas da vida cotidiana ${ }^{21}$, principalmente em relação ao trabalho médico e à amplitude das práticas de saúde. Estas práticas agregam o "saber de experiência feito" 22 , compõem um mosaico entre tecnologias formais e não formais, e têm por base informações e saberes científicos, envolvidos em relações objetivas permeadas de subjetividade.

Discutir as práticas de saúde pressupõe sua pluralidade e a diversidade de seus sujeitos, assim como as diferentes apropriações que a sociedade realiza dessas práticas. Nesta perspectiva, colocar em diálogo a prática médica com o conjunto das práticas de saúde encontra sentido na possibilidade de promover a autonomia dos sujeitos envolvidos (quem as realiza e quem as demanda) e superar a situação que gera e alimenta as necessidades de saúde da população e dos indivíduos.
Para tanto, o processo de ensino e aprendizagem difere da educação bancária ${ }^{23}$, que toma como pressupostos a ignorância, a passividade e a descontextualização dos educandos para reproduzir e naturalizar o status quo, e se aproxima da educação problematizadora, que reconhece os sujeitos da aprendizagem como portadores de saberes, e estes, no diálogo e na reflexão crítica, reconhecem a si mesmos como protagonistas de possibilidades de mudanças nesta realidade.

A Articulação Nacional de Extensão Popular em Saúde (Anepop), que desenvolve ações de extensão universitária na perspectiva da educação popular, tem promovido experimentações e vivências

[...] no contato com os movimentos populares de saúde, os movimentos sociais e sua luta cotidiana (em que) diversos estudantes vem apreendendo a importância de se abrir ao novo, percebendo os limites e inconsistências existentes em sua relação verticalizada com a população, bem como a inconclusão do próprio saber científico e acadêmico (p. 172) ${ }^{24}$.

Na atual gestão do SUS, ocorre um movimento de institucionalização da educação popular em saúde ${ }^{25}$, um campo em processo de constituição cujas práticas se desenvolvem em universidades em programas e projetos de extensão, como pesquisas, teses e dissertações, que têm contribuído com seu aprofundamento teórico conceitual e metodológico e se mostrado elemento central nas práticas de profissionais que atuam diretamente com os usuários na ponta do sistema, integrando políticas específicas, como a Política Nacional de Humanização, Atenção Básica, Promoção da Saúde.

\section{BRICOLAGEM — PRELIMINARES}

Os múltiplos significados de práticas de saúde e prática médica em particular abrangem uma diversidade de características que se expressam histórica e culturalmente, indicando a polissemia deste conceito. Conceitos polissêmicos têm como característica a capacidade de gerar significados que se mostram adaptáveis a diferentes contextos sociais, econômicos e políticos, que, tomados como significantes, resultam em políticas, programas e projetos sociais, que, embora alinhados a conceitos referendados, apresentam distintos sentidos a depender da situação conjuntural ${ }^{26}$, da posição epistemológica do pesquisador e do ambiente social da pesquisa ${ }^{27}$.

Neste sentido, a seleção e a ordenação do que é considerado importante a respeito dos fatos e conceitos concernentes às práticas de saúde seguem a intencionalidade do pesquisador, que constrói o olhar sobre o processo a partir da questão problematizadora: como a disciplina poderia abordar aspectos da 
prática médica como ações que potencializam os princípios de emancipação e autonomia dos sujeitos envolvidos?

O termo bricolagem vem do francês bricolage. É associado às atividades do tipo "faça você mesmo", para seu próprio uso ou consumo, sem o emprego de serviço profissional. No campo acadêmico, o termo ganha característica de técnica de pesquisa de campo, principalmente em pesquisas antropológicas, e uma dimensão metodológica por parte da corrente institucionalista francesa, que a considera o ato de construir referências de análise de objetos e situações complexas, com base em suas múltiplas expressões e dimensões.

Levy-Strauss $^{28}$ utilizou a bricolagem em sua obra Pensamento Selvagem como estratégia teórica e metodológica que permitiu a compreensão dos sistemas de classificação e ordenamento dos elementos da vida cotidiana de grupos populacionais distantes da cultura ocidental, civilizada. Para o autor, a tarefa da bricolagem não se subordina à produção de matéria-prima ou objetos;

é um conjunto finito de elementos e materiais diversificados e sua composição do conjunto é resultado contingente de todas as oportunidades que se apresentaram para renovar e enriquecer o estoque ou para mantê-lo com os resíduos de construções e destruições anteriores (p. 33).

Bricolagem não é somente uma técnica de investigação, mas

funciona com a mesma intensidade nos empréstimos que se faz a diversas escolas e teorias para fazê-las convergir para um mesmo objeto de pesquisa e, desta maneira, esclarecê-lo através de múltiplas perspectivas ${ }^{29}$ (p. 121)

Turato $^{30}$ coloca em relevo a figura do pesquisador como instrumento de pesquisa nas abordagens qualitativas em saúde, comparando sua atuação como um bricoleur (bricolador), que, segundo Chauíi1 , "produz um objeto novo a partir de pedaços e fragmentos de outros objetos. Vai reunindo, sem um plano muito rígido, tudo o que encontra e que serve para o objeto que está compondo" (p. 204).

Neste caso, a bricolagem conceitual necessária ao objetivo da pesquisa tem como universo as conexões que se estabelecem entre as dimensões da prática médica, o campo ético-político dos princípios do SUS e os princípios filosóficos de emancipação e autonomia como substrato da ação humana.

Considerando a prática médica como fenômeno multirreferencial, o pesquisador identifica os conceitos e significados que emergem dessas conexões, compondo um mosaico ${ }^{32}$ no qual é possível elencar os temas e possíveis conteúdos da disciplina.
Tendo como limite as condições estruturais da disciplina, ou seja, carga horária e a disponibilidade do tempo dos alunos na distribuição de outras disciplinas e condições para as atividades práticas, a fase final do trabalho foi organizar os conceitos referentes aos mosaicos resultantes, compondo as unidades temáticas.

\section{BRICOLAGEM - CONSTRUINDO SENTIDOS}

A polissemia do significado de práticas de saúde nas quais se insere a prática médica permite identificar e estabelecer relações com outras práticas que operam no amplo campo da saúde, com os princípios éticos e políticos do SUS e reiterar o sentido de emancipação e autonomia presentes como intencionalidade nos processos pedagógicos.

Frank et al. ${ }^{33}$ consideram a aprendizagem um processo que contempla três níveis sucessivos: informativo, formativo e transformador. A aprendizagem informativa se refere à aquisição de conhecimentos e habilidades, e seu objetivo é produzir especialistas; a aprendizagem formativa diz respeito à socialização dos educandos em torno de determinados valores, e seu objetivo é produzir profissionais; a aprendizagem transformadora, o mais alto dos três níveis, tem relação com o desenvolvimento de atributos de liderança, e seu objetivo é a produção de agentes de mudança conscientes e comprometidos.

Nesta perspectiva, a ação pedagógica tem o sentido de fortalecer a autonomia e promover a emancipação, tanto no processo ensino-aprendizagem como nas relações entre estudantes e comunidades de práticas de saúde nas quais transitam.

O sentido de autonomia e emancipação imbricado no processo de formação de médicos advém da implicação com a educação popular em saúde, pedagogia construtiva, reflexiva e criativa, que contribui para a constituição de sujeitos com capacidade de fortalecer sua autonomia, em virtude da leitura crítica de sua inserção no mundo, e desencadear movimentos que possibilitem sua emancipação, no sentido de superar situações que mantenham ou reproduzam a ideia de causalidade natural e determinística dos fenômenos envolvidos na saúde e na doença. É uma educação voltada para a transformação da sociedade, que toma como referência inicial a realidade vivenciada pelos educandos para construir, de forma coletiva, respostas às indagações: Por que é assim? Poderia ser diferente? A base dessa busca se encontra na curiosidade epistemológica, na problematização dos fatos, no diálogo e no protagonismo dos sujeitos ${ }^{34}$.

Stotz et al. ${ }^{35}$ apontam algumas possibilidades de a educação popular em saúde contribuir na constituição de sujeitos com consciência crítica e autonomia para atuarem na construção e na disputa de projetos políticos na perspectiva dos movimentos populares. A concepção popular de saúde se apresenta 
"como um mosaico, em que os fragmentos de experiências e saberes diversos presentes são usados como recursos de enfrentamento de certos problemas, de acordo com a ocasião, as possibilidades existentes e o que se acredita ser melhor" (p. 43).

Uma primeira sistematização dos objetos coletados permitiu perceber que: (a) os múltiplos significados de práticas de saúde evidenciaram a diversidade de atores que as desenvolvem, espaços específicos nos quais são realizadas e saberes que as fundamentam; (b) a multirreferencialidade das práticas de saúde permitiu estabelecer diálogo com outros campos disciplinares, caracterizando-as como práticas sociais, políticas, complexas e interdisciplinares; (c) a aproximação entre as práticas de saúde e os princípios do SUS depende da compreensão da saúde como direito e fenômeno socialmente determinado; (d) autonomia e emancipação dependem do sentido da prática pedagógica para os envolvidos.

A Figura 1 representa a maneira como a dimensão das práticas, os princípios do SUS, a autonomia e a emancipação se colocam em conexão.

FIgURA 1

Conexões entre as dimensões das práticas de saúde, os princípios do SUS e os movimentos de autonomia e emancipação dos sujeitos

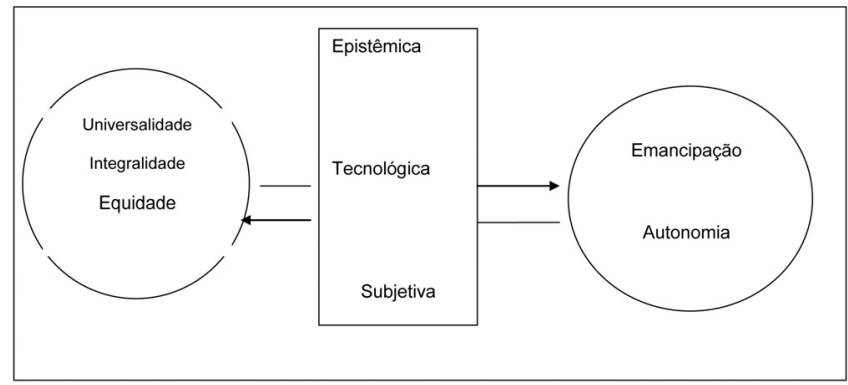

As dimensões que envolvem as práticas de saúde em geral e a prática médica em particular compreendem a episteme, ou seja, o plano do conhecimento geral reconhecido como ciência; a techne, a dimensão técnica que expressa o saber transformado em instrumento; e a dimensão da práxis, das interações subjetivas entre população, profissionais e gestores que acontecem nos espaços coletivos e os modos singulares como cada indivíduo vive, interpreta e expressa essas exigências ${ }^{6}$.

Qualquer uma dessas dimensões é compreendida como dispositivo que opera na mediação entre o movimento dos sujeitos sociais em direção à emancipação e à autonomia no que diz respeito à sua saúde, ou seja, quanto mais autonomamente for construído o significado de práticas de saúde como universais, integrais e equânimes, mais a expressão desses princípios nas ações realizadas emancipa os sujeitos sociais.
Ao mesmo tempo, a prática médica integrante do ato de cuidar revela possibilidades de aproximar o conhecimento produzido e acumulado na sociedade da organização das práticas nos serviços e do modo como os sujeitos envolvidos explicam e justificam seus problemas. Esta perspectiva diminui o know do gap existente entre o que se produz na academia e o que é incorporado na vida cotidiana como política pública ou como tecnologia nos serviços de atenção à saúde $\mathrm{e}^{36} \mathrm{e}$ a distância cultural entre profissionais e usuários ${ }^{37}$.

Com base na esquematização acima foram sendo construídas as conexões mais particulares entre cada dimensão das práticas de saúde, o SUS como cenário de sua realização e os sujeitos que produzem e consomem tais práticas.

\section{PRÁTICA MÉDICA E PRINCÍPIOS DO SUS}

O cruzamento entre as dimensões das práticas de saúde e os princípios do SUS (universalidade, equidade e integralidade) deu origem a espaços que foram preenchidos com objetos disponíveis que pudessem responder à pergunta: quais pressupostos são necessários para que cada dimensão das práticas de saúde seja compreendida em sua relação com os princípios do SUS?

\section{QuADRO 1}

Conexões entre as dimensões da prática médica e os princípios do SUS

\begin{tabular}{|c|c|c|c|}
\hline \multirow{2}{*}{$\begin{array}{l}\text { Princípios do } \\
\text { SUS }\end{array}$} & \multicolumn{3}{|c|}{ Dimensões da prática médica } \\
\hline & Epistêmica & Técnica & Subjetiva \\
\hline Universalidade & $\begin{array}{l}\text { Saúde como } \\
\text { produção social }\end{array}$ & $\begin{array}{l}\text { A produção } \\
\text { de saúde, de } \\
\text { conhecimento e } \\
\text { tecnologia }\end{array}$ & $\begin{array}{l}\text { Trabalho em } \\
\text { saúde }\end{array}$ \\
\hline Equidade & $\begin{array}{l}\text { Saúde é cultura } \\
\text { e direito de } \\
\text { todos }\end{array}$ & $\begin{array}{l}\text { Os diversos } \\
\text { modos de viver, } \\
\text { adoecer e morrer }\end{array}$ & $\begin{array}{l}\text { Os significados } \\
\text { das práticas } \\
\text { de saúde para } \\
\text { o profissional, } \\
\text { gestor e usuário }\end{array}$ \\
\hline Integralidade & $\begin{array}{l}\text { Saúde das } \\
\text { pessoas, dos } \\
\text { grupos, das } \\
\text { comunidades e } \\
\text { dos territórios }\end{array}$ & $\begin{array}{l}\text { Da assistência } \\
\text { ao cuidado: } \\
\text { educação em } \\
\text { saúde, promoção } \\
\text { da saúde }\end{array}$ & $\begin{array}{l}\text { Os serviços de } \\
\text { saúde na vida } \\
\text { cotidiana }\end{array}$ \\
\hline
\end{tabular}

Em uma leitura vertical do Quadro 1, a dimensão epistêmica da prática médica se conecta ao princípio de universalidade ao considerar a saúde como integrante do projeto civilizatório da humanidade, resultado da produção social na qual todos os sujeitos são protagonistas e responsáveis. A relação com a equidade se encontra no pressuposto de que são práticas de saúde orientadas por saberes que se encontram na cultura e na diversidade dos sujeitos, cidadãos, portadores de direitos, entre os quais a saúde é essencial. 
A conexão com o princípio da integralidade se faz pela expressão dessas práticas, sejam promocionais, preventivas e de cuidado, nos modos de vida de indivíduos, grupos e comunidades.

Na dimensão técnica, a prática médica se aproxima da universalidade do direito à saúde quando o acúmulo técnico e científico se mostra resultado da produção e socialização do conhecimento e inovações tecnológicas, enquanto a perspectiva da equidade considera o acesso, a utilização e a ética das tecnologias diante de diversos modos de viver, adoecer e morrer das pessoas e comunidades.

A integralidade da prática médica somente pode ser compreendida sob a concepção de tecnologias para o cuidado em saúde, na qual se incluem as tecnologias leves presentes nas ações de promoção e educação em saúde, superando o pensamento de que tecnologia dura é o único suporte para a qualidade da atenção.

Na dimensão subjetiva, da práxis, o trabalho em saúde é o elemento que sintetiza o saber, a técnica e o agir, presente como devir ou de forma concreta na vida dos estudantes e trabalhadores de saúde. O trabalho médico se aproxima do SUS compreendido em sua universalidade como trabalho humano - ou seja, um processo que envolve os meios e as condições de sua produção - , e em sua singularidade de ser um trabalho que se realiza na relação entre o saber de um e o sofrer de outro e ter seu produto consumido durante sua própria produção.

A dimensão subjetiva do trabalho médico compreende os vários significados que este processo suscita pelo predomínio da produtividade sobre a qualidade, de sua realização sob organização hierarquizada de especialidades e subespecialidades ofertadas de maneira diferenciada, produzindo iniquidades nos modos e espaços de produção e em seu consumo como valor de uso ou valor de troca ${ }^{38}$.

Nos serviços de saúde, a prática médica se concretiza em ato que permite aos envolvidos a expressão subjetiva a respeito do seu significado; para os profissionais, que a partir do arsenal de conhecimentos, habilidades e competências esperam realizar o que consideram uma boa prática, e para os usuários, que esperam que essa prática satisfaça sua necessidade. Nesse espaço, a integralidade é possível com base na no diálogo e na construção do consenso do que sejam boas práticas de saúde para ambos.

Em seguida, foram preenchidos os espaços resultantes do cruzamento entre as dimensões das práticas de saúde e a prática pedagógica com base no questionamento sobre como abordar o tema e a possibilidade de suscitar o sentido de autonomia e emancipação dessas práticas por seus sujeitos.

\section{PRÁTICA MÉDICA, AUTONOMIA E EMANCIPAÇÃO}

Os princípios de autonomia e emancipação e as dimensões da prática médica foram cruzados e preenchidos pela bricolagem feita com os objetos relacionados à questão: quais os pressupostos necessários para que a abordagem dessa prática produza sentido de autonomia e emancipação por parte de seus produtores e usuários? (Quadro 2).

\section{QuAdro 2}

As dimensões da prática médica e os princípios da pedagogia da autonomia

\begin{tabular}{|c|l|l|l|}
\hline \multirow{2}{*}{$\begin{array}{c}\text { Princípios da } \\
\text { Pedagogia da } \\
\text { Autonomia }\end{array}$} & \multicolumn{1}{|c|}{ Eimensões da prática médica } \\
\cline { 2 - 4 } Autonomica & \multicolumn{1}{|c|}{ Técnica } & \multicolumn{1}{c|}{ Subjetiva } \\
\hline prise de conceitos e & $\begin{array}{l}\text { Modelos } \\
\text { tecnoassistenciais }\end{array}$ & $\begin{array}{l}\text { Saber } \\
\text { compartilhado }\end{array}$ \\
\hline Emancipação & $\begin{array}{l}\text { Historicidade do } \\
\text { conceito de saúde/ } \\
\text { doença/prática } \\
\text { médica }\end{array}$ & $\begin{array}{l}\text { Racionalidades } \\
\text { médicas }\end{array}$ & $\begin{array}{l}\text { Alteridade na } \\
\text { fala e na escuta }\end{array}$ \\
\hline
\end{tabular}

Uma pedagogia da autonomia é centrada em experiências estimuladoras da decisão e da responsabilidade, pois, segundo Freire ${ }^{34}$, a autonomia vai se constituindo na experiência de várias, inúmeras decisões que vão sendo tomadas - "ninguém é autônomo primeiro para decidir depois" (p. 107). Nesta perspectiva, a autonomia conduz à emancipação, ou seja, à intencionalidade política declarada e assumida por todos os comprometidos com a transformação das condições e de situações que impõem limites à vida humana.

O sentido de prática pedagógica tem como referência uma abordagem que privilegia sua contemporaneidade e o protagonismo dos sujeitos sociais e valores éticos prevalentes em cada contexto, incertezas e imperfeições, porquanto produtos da ação de sujeitos sociais em constituição, não acabados, que constroem sua existência.

Como prática social, o sentido de emancipação e autonomia é percebido na forma de organização dessas práticas sob determinadas racionalidades que se expressam em tecnologias que podem contribuir para a libertação ou aprisionamento dos sujeitos ao fetiche tecnológico. ${ }^{39}$

Na dimensão da práxis, acontece o encontro entre racionalidades distintas e a interação entre a subjetividade de quem produz e de quem recebe o ato resultante da prática médica. $\mathrm{O}$ movimento de emancipação e autonomia encontra-se na possibilidade de compartilhamento e diálogo entre os saberes que orientam as distintas racionalidades, da alteridade na fala e na escuta, na construção de projetos de vida mais saudável. 
Na perspectiva da emancipação, a prática médica, em sua dimensão epistêmica, é resultante e integra conceitos e paradigmas em cujas crises existem possibilidades de irrupção de outros paradigmas; é componente essencial na configuração dos modelos assistenciais, embora não seja o único elemento constituinte do cuidado em saúde. A possibilidade de emancipação se estabelece quando o compartilhamento de saberes vivenciados pelos sujeitos sociais (usuários e profissionais) orienta práticas voltadas à produção da saúde e da vida.

\section{UNIDADES TEMÁTICAS E CONTEÚDO DA DISCIPLINA IPS}

A síntese dos conteúdos dos quadros (mosaicos) construídos representou a base para a definição das unidades temáticas e o conteúdo da disciplina. O eixo condutor dessa construção foi a concepção de prática médica como ação humana, fundamentada em conhecimento e racionalidades científicas, que, ao se transformar em ato, inclui o portador de outra racionalidade e outra subjetividade com capacidade de anular ou potencializar a prática.

\section{QuAdro 3}

Unidades temáticas e conteúdos selecionados

\begin{tabular}{|l|l|}
\hline \multicolumn{1}{|c|}{ Unidades temáticas } & \multicolumn{1}{c|}{ Conteúdos } \\
\hline $\begin{array}{l}\text { Unidade I: A historicidade } \\
\text { da prática médica }\end{array}$ & $\begin{array}{l}\text { A historicidade do significado de } \\
\text { saúde e doença com ênfase nos } \\
\text { movimentos da sociedade. Crise dos } \\
\text { conceitos e paradigmas. Emergências } \\
\text { de outras racionalidades. Produção e } \\
\text { utilização social do conhecimento em } \\
\text { saúde }\end{array}$ \\
\hline $\begin{array}{l}\text { Unidade II: A prática } \\
\text { médica e o cuidado com } \\
\text { os indivíduos, grupos e } \\
\text { sociedade }\end{array}$ & $\begin{array}{l}\text { Normal e patológico. Modos de andar } \\
\text { a vida. Normatividade. Determinantes } \\
\text { sociais da saúde. Como vivem } \\
\text { as pessoas, como adoecem e são } \\
\text { cuidadas. Mudanças nos perfis } \\
\text { epidemiológicos. Fragmentação, } \\
\text { tecnificação e monetarizaça da } \\
\text { prática médica. Educação popular } \\
\text { em saúde. Promoção da Saúde. } \\
\text { Humanização da saúde. Equidade em } \\
\text { saúde }\end{array}$ \\
\hline $\begin{array}{l}\text { Unidade III: A prática } \\
\text { médica e as transformações } \\
\text { no mundo contemporâneo }\end{array}$ & $\begin{array}{l}\text { As mudanças nos paradigmas das } \\
\text { práticas médicas e as mudanças } \\
\text { sociais. A reforma sanitária brasileira. } \\
\text { O SUS e a participação social }\end{array}$ \\
\hline
\end{tabular}

As três unidades temáticas são pressupostos provisórios resultantes das conexões entre os objetos que emergiram no cruzamento entre a prática médica e os princípios do SUS; o ensino da disciplina IPS na perspectiva de uma pedagogia capaz de suscitar o sentido de autonomia e emancipação do professor e dos estudantes em relação ao tema; e uma concepção crítica, transformadora e criativa, que possibilite ao profissional médico a consciência de ser sujeito de suas práticas.

I: Práticas médicas integram as práticas de saúde e resultam da ação de sujeitos sociais históricos portadores de direitos, deveres e saberes;

II: Práticas médicas são práticas de saúde específicas e singulares que colocam em relação sujeitos portadores de saberes e vivências fundamentados em distintas racionalidades que podem se articular na integralidade do cuidado;

III: Práticas médicas, assim como as práticas sociais, expressam possibilidades de superação do conhecimento atual e da situação vivenciada.

Para cada unidade temática foram sistematizados os conteúdos apresentados no Quadro 3.

\section{CONSIDERAÇÕES FINAIS}

A seleção do conteúdo da disciplina IPS resultou da bricolagem com o material existente sobre o tema Práticas de Saúde, que possibilitou ordenar e conectar questões e dimensões da prática médica aparentemente isoladas e invisíveis.

Este processo representou uma estratégia metodológica e técnica de ordenação de objetos dispersos em diversas dimensões, expressões e formatos, cujo sentido, atribuído intencionalmente pelo pesquisador, definiu conteúdos e formas de abordagem de temas polissêmicos.

Em decorrência da intencionalidade do pesquisador, bricoleur, resultados e conteúdos são sempre provisórios, suscetíveis a rupturas, adaptações e transformações.

Como temas polissêmicos, prática médica e prática de saúde necessitam permanentemente de contextualização para adquirir significado construído por seus sujeitos. E, nesse caso, utilizando a bricolagem como processo de ordenar e produzir sentido em objetos empíricos diversos, foi possível selecionar conteúdos articulados a abordagens pedagógicas produtoras de sentido.

\section{REFERÊNCIAS}

1. Frenk J, Chen L, Bhutta ZA, Cohen J, Crisp N, Evans Timothy et al. Profesionales de la salud para el nuevo siglo: transformando la educación para fortalecer los sistemas de salud en un mundo interdependiente .Rev Peru Med Exp Salud Publica. 2011;28(2):337-41.

2. Canesqui AM. Ciências Sociais e Saúde no ensino médico. In: Canesqui AM, org. Ciências Sociais e Saúde para o Ensino Médico. São Paulo: Hucitec; 2003. p.25-48.

3. Haddad AE, Brenelli SL, Cury GC, Puccini R, Martins MA, Ferreira JR, Campos FE. Pró-Saúde e PET-Saúde: a cons- 
trução da política brasileira de reorientação da formação profissional em saúde[Editorial

4. ]. Rev Bras Educ Med. 2012: 1(36): 3-4

5. Merhy EE. Saúde: a cartografia do trabalho vivo. São Paulo: Hucitec; 2002

6. Buss P M. Saúde pública hoje. In Hortale VA, Moreira COF, Bodstein RCA, Ramos CL, (org.). Pesquisa em Saúde Coletiva: fronteiras, objetos e métodos. Rio de Janeiro: FIOCRUZ; 2010.

7. Ayres JR, Para comprender el sentido práctico de las acciones de salud: contribuciones de la hermenêutica filosófica. Salud Coletiva. 2008;4(2):159-72.

8. Gadamer Hans-Georg. O caráter oculto da saúde. Petrópolis: Vozes; 2006.

9. Batista SHS. A interdisciplinaridade no ensino médico. Rev Bras Educ Med. 2006:30(1):39-46.

10. Bourdieu P. Método científico e hierarquia social dos objetos.In: Nogueira MA, Catani A, org.. Pierre Bourdieu: escritos de educação. $7^{\mathfrak{a}}$ ed. Petrópolis: Vozes;2005. p.33-9.

11. Starr P. The social transformation of american medicine. New York: Basic Books; 1982.

12. Facchini LA, Piccini RX, Santos RC, (org.). CINAEM - Preparando a transformação da educação médica brasileira. Projeto CINAEM, III Fase. Relatório 1999-2000. Pelotas:UFPel; 2000.

13. Universidade Federal do Piaui. Projeto Pedagógico do Curso de Medicina. Março/1999. [acesso em 29 set. 2012]. Disponível em: http://www.ufpi.br/subsiteFiles/cc/arquivos/files/medicina_cmpp.pdf.

14. Brasil. Ministério da Saúde/Conselho Nacional de Saúde. $12^{\text {a }}$ Conferencia Nacional de Saúde Brasília: Conselho Nacional de Saúde; 2003. (Relatório Final).

15. Brasil. Ministério da Saúde/Conselho Nacional de Saúde. III Conferencia Nacional de Gestão do Trabalho e da Educação na Saúde. Brasília: Conselho Nacional de Saúde; 2005. (Relatório Final).

16. Brasil. Presidência da República. Programa Saúde na Escola. Decreto № 6286 de 05 de dezembro de 2007. Institui o programa Saúde na Escola e dá outras providências. [acesso em 2 out. 2012]. Disponível em:http:/ /www.crn6.org. br/legislacao.

17. Brasil. Ministério da Saúde. Secretaria de Gestão do Trabalho e da Educação na Saúde. Departamento de Gestão da Educação na Saúde. Política de Educação Permanente para o SUS. Brasília: Ministério da Saúde; 2004

18. Brasil. Ministério da Educação. Conselho Nacional de Educação. Câmara de Educação Superior. Resolução n.4, CNE/CES de 7/11/2001. Institui diretrizes curriculares nacionais do curso de graduação em medicina. Diário Oficial da União. Brasília, 9 nov. 2001; Seção 1, p. 38. Disponível em:URL: http://portal.mec.gov.br/cne/arquivos/ pedf/

19. Koifman L, Oliveira-Saippa G. Produção de conhecimento e saúde. In Pinheiro R, Ceccim RB, Mattos RA, (org.). Ensinar saúde: a integralidade e o SUS nos cursos de graduação na área de saúde. Rio de Janeiro: CEPESC:IMS/ UERJ:ABRASCO; 2011. p.111-30

20. Associação Brasileira de Educação Médica [homepage]. Rio de Janeiro:ABEM [acesso em 4 jan. 2012]. 49ํㅡㄹ Congresso Brasileiro de Educação Médica. 12 a 15 nov. 2011; Belo Horizonte-MG. Disponível em:HTTP:/ /WWW.cobem.br.

21. Madsen W, Bell T. Using health promotion competencies for curriculum development in higher education. UIPES Global Health Promotion. 2012;19(1):43-9.

22. Schön DA. Educando o profissional reflexivo: um novo design para o ensino e a aprendizagem. Porto Alegre: . Artes Médica; 2000

23. Freire P. À sombra desta mangueira. São Paulo: Olho d'Água; 1995

24. Freire P. Pedagogia do Oprimido. 5a ed. Rio de Janeiro:Paz e Terra;1978

25. Cruz PJ. Extensão universitária popular como lugar ressignificador da atenção primária em saúde. In Mano MAM, Prado EV (org). Vivencias de Educação Popular na Atenção Primária à Saúde: a realidade e a utopia. EduSFCAR: São Carlos-SP; 2010. p. 167-74.

26. Pedrosa JIS. Educação Popular no Ministério da Saúde: identificando espaços e referências. Cad Educ Popular Saúde. 2007. p.13-17

27. Ridde V. Reducing social inequalities in health: public health, community health or health promotion? IUHPE Prom Educ. 2007;14(2):63-71.

28. Ridde V. Equity and health police in Africa: using concept mapping in Moore. BMC Health Serv Res. 2008;8:90. DOI: 10.1186/1472-6963-8-90

29. Lévi-Strauss C. O Pensamento Selvagem. $8^{\underline{a}}$ ed. Paiprus: São Paulo; 2006.

30. Lapassade G. A multirreferencialidade como bricolagem.. In: Barbosa JG, (org.). Multirreferencialidade nas ciências e na educação. São Carlos: EdUFSCar; 1998. p.126-48.

31. Turato ER.Introdução à metodologia da pesquisa clínico-qualitativa: definição e principais características.Rev Portuguesa Psicossomatica. 2000;2(1):93-108.

32. Chaui MS. Convite à Filosofia. $3^{\underline{a}}$ ed. São Paulo: Ática; 2000.

33. Deleuze G. Diferença e repetição. Graal: Rio de Janeiro; 1988 
34. Frenk J, Chen L, Bhutta ZA, Cohen J, Crisp N, Evans Timothy, et al. Profesionales de la salud para el nuevo siglo: transformando la educación para fortalecer los sistemas de salud en un mundo interdependiente .Rev Peru Med Exp Salud Publica. 2011;28(2):337-41.

35. Freire P. Pedagogia da autonomia. $30^{\underline{a}}$ ed. São Paulo:Paz e Terra.

36. Stoz E. Enfoques sobre educação popular e saúde. In: Ministério da Saúde, Secretariade Gestão Estratégica e Participativa, Departamento de Apoio à Gestão Participativa. Caderno de educação popular e saúde. Brasília: MS; 2007. p.46-57.

37. Guimarães MCS. Uma geografia para a ciência faz diferença: um apelo da Saúde Pública. Cad Saúde Pública. 2010;26(1):50-8.

38. Valla VV. Sobre participação popular: uma questão de perspectiva. Cad Saúde Pública. 1998;14(Supl. 2):7-18.
39. Merhy EE. Saúde: a cartografia do trabalho vivo. São Paulo: Hucitec; 2002

40. Escossia L. Por uma ética da metaestabilidade na relação homem-técnica. In: Pelbart PP, Costa R, (orgs.) Cadernos de Subjetividade: o reencantamento do concreto. São Paulo: Hucitec; 2003.

\section{CONFLITO DE INTERESSES}

Declarou não haver.

\section{ENDEREÇO PARA CORRESPONDÊNCIA}

Universidade Federal do Piauí - Núcleo de Estudos em Saúde Pública

Campus Universitário Ministro Petrônio Portela

Ininga - Teresina

CEP 64049-550 PI

E-mail: jivopedrosa@gmail.com 